\title{
Extreme Variability of the Tropical Tropopause over the Indian Monsoon Region
}

\author{
VANMATHI A., S. K. MEHTA, and B.V. KRISHNA MURTHY \\ SRM Research Institute, SRM University, Kattankulathur, Tamil Nadu, India
}

\begin{abstract}
Cold point tropopause (CPT) plays a significant role to entry of water vapor into the lower stratosphere. Thus the variation in the tropopause plays an important role in the climate change by modifying the distribution in the stratospheric water vapor and hence the global radiation budget. The seasonal variability of the CPT is well known. During winter season, CPT is colder and higher but there are occasions when they observed to be warmer and lower.Similarly, during the summer season CPT is warmer and lower, however, we observed several cases when it becomes colder and higher. Not only this, there are several occasions when tropopause varies extremely. Thus, in this study, we have proposed a method to identify the extreme variability such as the coldest, warmest, highest and lowest tropopauses and examine the thermal their structure.Extreme variability of the cold point tropopause temperature (CPT-T) and height (CPT-H) are examined over a tropical station, Gadanki (13.45 N, 79.2 E)using high resolution radiosonde data during period 2006-2014. The extreme variabilities in the CPT-T and CPT-H are identified based on the $2 \sigma$ (standard deviation) departure from their monthly mean. In total 192 extreme cases such as the coldest (53) and warmest (41) CPT-T and the highest (61) and lowest (37) CPT-H are observed. The coldest $(190 \pm 5 \mathrm{~K}, 17 \pm 2 \mathrm{~km})$, warmest $(190 \pm 5 \mathrm{~K}, 17 \pm 2 \mathrm{~km})$, lowest $(190 \pm 5 \mathrm{~K}, 17 \pm 2 \mathrm{~km})$ and highest $(190 \pm 5 \mathrm{~K}, 17 \pm 2$ $\mathrm{km}$ ) occurs without preference of season. Thermal structure of the coldest tropopause reveal that they often occur sharper with tropopause temperature and height are $189.3 \mathrm{~K}$ and $17 \mathrm{~km}$, respectively. These cases are important for freeze drying mechanism. Whereas for all other cases such as the warmest, highest and lowest tropopause are broader in nature.Possible mechanisms responsible for such extreme variabilities such as equatorial wave propagation, deep convection and ozone transport are examined.
\end{abstract}

